\title{
Correspondence
}

\section{Right atrial-pulmonary artery anastomosis: a historical note}

Sir,-In 1966 a short case report on this subject was included in a paper entitled "New operations in children's cardiac disease," published in Surgical Clinics of North America (Rams et al, 1966). This case report was entitled "Total correction of tricuspid atresia" and concerned a girl, aged 16 months, who had a Glenn procedure in October 1958. In 1960 a right atrial-pulmonary artery anastomosis was performed, as shown in fig 7 of the paper. In April 1961 the atrial septal defect was closed. She did well for 24 hours, but then developed renal failure and hyperkalaemia and had a cardiac arrest. Figure 1 is from the 1966 publication with labels to correspond to those of fig 2, the anatomical specimen. This is No 927 (University of Chicago) and A12075-61 in the anatomical collection at the Congenital Heart Disease Research and Training Center at the Hektoen Institute in Chicago.

The reference has not been included in subsequent references to this bypass operation. This surgical

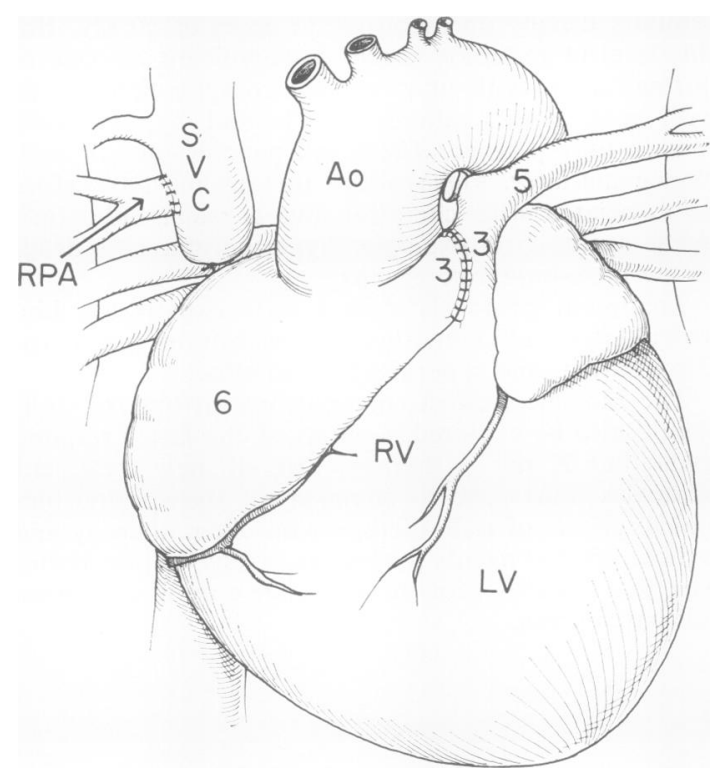

Fig 1 Redrawn from fig 7 of the original report $(B y$ courtesy of $W B$ Saunders $C o$ ).

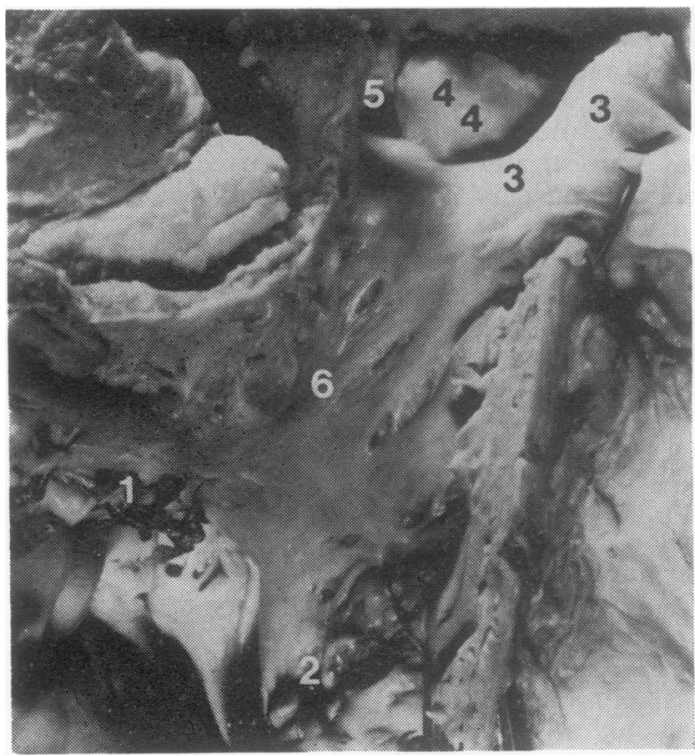

Fig 2 Anatomical specimen. Labels of both figures refer to the same areas: (1) recent sutures closing atrial septal defect, (2) atriotomy closure by suture, (3) a roof of right atrial appendage and part of pulmonary artery opened and pulled aside, (4) part of pulmonary valve, (5) atrial appendage opening into main and left pulmonary artery, and (6) right atrium.

procedure, right atrial-pulmonary artery bypass, was described in more detail by Fontan and Baudet (1971).

Dr Cassels was professor of pediatrics, pediatric 3 cardiology and Dr Moulder was professor of surgery, cardio-thoracic surgery, at the University of Chicago in 1961 .

DONALD E CASSELS

PETER V MOULDER N University of Chicago, Chicago, USA

\section{References}

Fontan, F, and Baudet, E (1971). Surgical repair of tricuspid atresia. Thorax, 26, 240-248.

Rams, J J, Daicoff, G R, Cassels, D E, and Moulder, P V (1966). New operations in children's cardiac ? disease. Surgical Clinics of North America, 46, 182184. 